\title{
The Changing Context of Psychology
}

Today psychology is positioned at a historical crossroads where its internal as well as external contexts are undergoing transformation in significant ways. In the course of its expansion during the twentieth century the discipline evolved with a distinct emphasis on individualization and making it a predominantly empirical project. The result is a tremendous growth of the discipline which is evident by its presence in different sectors and the enormous volume of publications. It has pervasively influenced and changed both society at large and our common understanding of ourselves. It has impacted almost all domains of life including education, child rearing, work, and mental health; thereby acknowledging psychologists as key players in human life. Provisions for an autonomous institutional structure provided the necessary mechanisms to pursue the various professional activities (e.g., counseling, psychological testing, training, personnel selection, therapy) and facilitated the growth of the discipline.

Professional psychology has gained a prominent position in the public imagination. Societies now frequently turn to psychology for help in solving their diverse problems and psychologists are increasingly being deployed in designing social management in the capacity of professional experts. Popular psychology books are proliferating. Indeed, psychologization of societies, with the individual as its central focus, has become one of the most important characteristics of the twenty first century. Individualization also led to the proliferation and acceptance of helping professions.

It may be worth noting that the twin processes of psychologization and individualization share a dialectic relationship. The emergence of psychological perspective as a legitimate mode of construing reality was an outcome of the process of individualization. It can be easily discerned that a shift from 'collective' to 'individual' did enhance the interest in individuality and paved the way for endeavors to make individual minds and behaviors as the discipline's main focus. At the same time psychology contributed to individualistic ideas and practices. The rise of individualism has been reciprocated by communication revolution, social mobility, individual freedom and a promotion of liberal attitudes. Although these changes opened new options for action, they also led to doubts and loss of anchors enjoyed during earlier periods. These anchors had provided individuals with a time proven world view of life, termed as the traditional or accepted ways of life. Changes in the milieu call for shifts in ways of thinking and new strategies.
Underlying the above engagements of the discipline has been a strong positivist conviction that scientific knowledge is progressive and value free. As such its prime goal was concerned with cumulative advancement of objective knowledge about reality on the basis of empirically collected data. The consequent applications of psychology were based on an optimistic belief that knowledge so generated is always for human welfare. This construal of psychology, however, carried the imprints of prevailing social preconceptions and ideological biases.

It may also be noted that individualization became a multifaceted cultural process. It involved a high degree of self-focus which promotes an emphasis on personal and emotional life. Social management (or application of psychology) is governed by a deliberate effort to direct or regulate/control the behavior of individuals and communities. Thus the processes of social management and individualization not only furnished the grounds for the emergence of professional psychology but also influenced the concepts and techniques employed by psychologists. This pattern of confluence makes the distinction between objective/factual knowledge and values quite problematic. Perhaps both function within the existing modes of practices and it is the culturally prevalent conceptions that lead the way rather than the scientific advances.

While the enterprise of psychology has evolved under the contingencies of history, culture and geographical settings, for long their recognition has been denied. Recent critical studies of the history of psychology show that psychology has been a culturally embedded enterprise. Now it is clear that the changes in the political structure, increase in productive activity and expansion of university system have provided major impetus for the expansion of psychology. Before World War II it was multi-centric but the following rise of United States as an economic and political power led to similar changes in the world of academia. American psychology became the norm for doing psychology, and scientific communications became dominated by American publications. In the nonwestern countries Western psychology was imported as a part of the process of making the host country modern. It arrived in most of these countries during colonization. The flow of influence, therefore, was one way and formal institutional and academic frameworks were organized according to the colonial dictates. The post colonial scenario has been shaped by several local and global factors. The disciplinary 
developments in these countries provide little support to indicate that western psychology is value-free, universal, and objective as it was projected. Instead, it was found to be deeply entrenched in the Euro-American cultural values of the rational and liberal individual. It stood in contrast to the notion of human beings as multilayered structures in a web of inter-relatedness.

In recent years there has been growing recognition that psychological science is a cultural enterprise that must examine its implicit assumptions and integrate with other world views in developing a truly universal psychological science However, in practice the relationship of culture with psychology has been approached from several perspectives and at different levels. This was expected since culture engages many disciplines and invites a range of theoretical alternatives. The existence of cultural diversity is beyond doubt as we notice a variety of physical and behavioural differences within and between various geo-political boundaries. Ethnicity, language and other symbolic systems, customs, institutions, religion, dress, and food habits are physical markers distinguishing different cultures. Taken together cultures represent the way of life, a world view and a meaning system shared by people. They are distributed in the minds of people as well in the ecology that they inhabit.

As a broad overarching concept culture is also used to signify the aspirations of a group of people. It articulates a potential zone of imagination and accomplishment with considerable affective investment of its participants. It is represented, assimilated and enacted by the group members. It results in similarities as well as differences across communities. It informs distinct identities and ways of being. Within psychology, perspectives like cross-cultural, cultural and indigenous have emerged which explore culture and assign different roles to it in psychological investigations.

This issue of Psychological Studies carries two contributions by Smith and Hwang that throw light on some important issues and developments pertaining to these approaches. Also, there is a comprehensive review by Sharma and Sharma on well-being in relation to self and identity as situated in cultural context. Other contributions also exemplify that we need to take culture seriously as a resource for concepts and insights into problem solving.

In today's world, the environmental crisis, population growth, technological advances and information revolution are shaping human civilization in unique and unprecedented ways. The emerging crises in the social sphere indicate that technological innovations are not enough. In order to handle existing problems, resolving them and fashioning the future, psychologists need to develop a sensibility to appreciate cultural processes. Such a move is imperative in contemporary times when multiculturalism has become a reality and with it emerges the issue of providing freedom to live according to culturally specific value systems. We need to outgrow the deep rooted preoccupation with dichotomies such as individualism-collectivism, cognition-emotionality, free will-determinism, and materialism-spiritualism. These appear to be dimensions that coalesce together and create divergent world views. People cannot be categorized in eitheror terms. Perhaps integrating indigenous and contemporary cultural practices require us to build conceptual bridges.

Recent years have witnessed increasingly greater degree of elf reflection and questioning about the nature, boundaries and ways of knowing reality. The traditionally privileged positivist and empiricist methods are being questioned and qualitative and interpretive methods are receiving attention from different quarters. The same, however, has been viewed by psychologists in different ways. The reactions of threat, anxiety, and challenge have been shown. Some have welcomed it and have engaged themselves in developing new psychologies. Going beyond the empiricist epistemology has enabled psychologists to raise a range of new questions. The move towards discourse, interpretation, subjectivity and cultural context has been an enriching and invigorating experience.

We need to ensure that the psychological knowledge should contribute to our material and spiritual well-being and should not act as a new source of oppression and control. Today we are faced by multitude of problems in different domains of life. A constructive response to them would require us to respect plurality and multiculturalism in our academic as well as professional lives and expand our conceptual and methodological tool kit to address the emerging issues. 